Results: The microtissues presented a core of SSc fibroblast as revealed by vimentin staining and an external layer of keratinocytes as revealed by cytokeratin 10 staining, mimicking the human skin architecture. Gene expression analysis following TGF $\beta$ stimulation displayed induced expression of extracellular matrix gene COL1A1 $(p=0.044)$ and the myofibroblast marker ACTA2 $(p=0.018)$, indicating that the microtissues were able to develop a fibrotic response. Microtissues, where $\mathrm{H} 19 \mathrm{X}$ was silenced, displayed reduced gene expression of COL1A1 and ACTA2 after TGF $\beta$ stimulation (COL1A1 $\mathrm{p}=0.007$, ACTA2 $\mathrm{p}=0.045)$. Additionally, $\mathrm{H} 19 \mathrm{X}$ silencing led to lower levels of $\alpha$ SMA protein expression $(\mathrm{p}=0.009)$ and pro-collagen $1 \alpha 1$ secretion $(p=0.039)$ in the supernatant of the microtissue cultures as revealed by Western Blot and ELISA, respectively. FN1 expression and fibronectin protein levels were not significantly reduced in the microtissues after H19X silencing.

Conclusion: We were able to produce a 3D microtissue resembling skin architecture that can respond to fibrotic stimuli. Knockdown experiments of pro-fibrotic IncRNA H19X confirmed the potential of the model as screening platform for novel pro-fibrotic effectors. A future aim will be to optimize the model for high-throughput automated screening platforms.

REFERENCES:

[1] Pachera, E., et al. (2020). "Long noncoding RNA H19X is a key mediator of TGF- $\beta$-driven fibrosis." The Journal of Clinical Investigation 130(9): 4888-4905.

Disclosure of Interests: Elena Pachera: None declared, Gabriela Kania: None declared, Astrid Juengel: None declared, Maurizio Calcagni Speakers bureau: Arthrex, Consultant of: Medartis, Arthrex, SilkBiomaterials, Grant/research support from: Medartis, Oliver Distler Speakers bureau: Actelion, Bayer, Boehringer Ingelheim, Medscape, Novartis, Roche, Consultant of: Abbvie, Actelion, Acceleron Pharma, Amgen, AnaMar, Arxx Therapeutics, Bayer, Baecon Discovery, Blade Therapeutics, Boehringer, CSL Behring, ChemomAb, Corpuspharma, Curzion Pharmaceuticals, Ergonex, Galapagos NV, GSK, Glenmark Pharmaceuticals, Inventiva, Italfarmaco, iQvia, -Kymera, Medac, Medscape, Mitsubishi Tanabe Pharma, MSD, Roche, Sanofi, UCB, Grant/research support from: Abbvie, Actelion, Bayer, Boehringer Ingelheim, Kymera Therapeutics, Mitsubishi Tanabe DOI: 10.1136/annrheumdis-2021-eular.3306

\section{OP0249 SERUM PROTEOMIC BIOMARKERS DEFINE PATIENTS WITH SYSTEMIC SCLEROSIS WITH INTERSTITIAL LUNG DISEASE}

M. De Santis ${ }^{1}$, N. Isailovic ${ }^{1}$, A. Ceribelli ${ }^{1}$, F. Motta $^{1,2}$, M. Vecellio ${ }^{2,3}$, C. Selmi ${ }^{1,2}$. ${ }^{1}$ Humanitas Clinical and Research Center - IRCCS, Rheumatology and Clinical Immunology, Rozzano, Italy; ${ }^{2}$ Humanitas University, Department of Biomedical Sciences, Pieve Emanuele, Italy; ${ }^{3}$ University of Oxford, Botnar Research Center, Nuffield Department of Orthopaedics, Rheumatology and Musculoskeletal Sciences, Oxford, United Kingdom

Background: Systemic sclerosis (SSc) is a systemic condition affecting multiple organs and thus being burdened by high morbidity and mortality; disease management is based largely on the early detection of organ involvement, particularly in the case of interstitial lung disease (ILD), ideally through noninvasive biomarkers. Beside serum autoantibodies associated with diffuse SSc, there is currently no reliable serum marker to predict the onset of SSc organ involvement, monitor its progression, and foresee the response to treatments. Proteomic analysis based on aptamer technology is a powerful method with the potential to address this unmet need in SSc.

Objectives: To identify serum biomarkers associated with ILD in SSc.

Methods: Serum samples from 6 women with SSc (3 with ILD at high-resolution pulmonary CT scan) and 7 age-matched female healthy controls (HC) were analyzed using the SOMAscan platform (SomaLogic, Inc., Boulder, CO, USA) to test more than 1300 proteins even at femtomolar concentration. Subsequent validation of candidate proteins was performed using ELISA in an independent cohort of 88 patients with SSc and $48 \mathrm{HC}$. Statistical analysis included Student's t-test and was assessed using the SomaSuite software (SomaLogic, Boulder, CO, USA)

Results: The proteomic analysis identified 33 proteins with significantly different serum levels in SSc cases compared to $\mathrm{HC}$ and 9 proteins differentiating SSc patients according to ILD (Table 1). Compared to HC, SSc sera manifested an altered expression of proteins involved in extracellular matrix formation and cellcell adhesion (with higher Calpain, EphA5, IDS, MATN2, MMP-12, TNR4, and lower desmoglein-1, SNP25), angiogenesis (with higher anti-angiogenetic factors as angiopoietin-2 and kininogen high molecular weight) lymphocyte recruitment, activation, and signaling (with higher CXCL-1, LAG3 and lower SH21A) with an overall inhibition of neutrophil function (with lower G-CSF-R, CD177, calgranulin B).
Table 1. Significantly altered proteins at serum proteomic analysis of systemic sclerosis (SSc) with or without interstitial lung disease (ILD) and healthy controls (HC)

\begin{tabular}{lccc}
\hline SSc versus healthy controls & & $\begin{array}{c}\text { SSc with ILD versus SSc } \\
\text { without ILD and healthy } \\
\text { controls }\end{array}$ \\
\hline Increased & Reduced & Increased & Reduced \\
Aldolase A & Adrenomedullin & FCRL3 & BAFF \\
Angiopoietin-2* & ASGR1 & IL-22BP** & DERM \\
C1QR1 & C1s & MCP-3 & \\
Calpain & C5 & PDE11 & \\
COLEC12 Eotaxin & Calgranulin B & PGP9.5 & \\
EphA5 & CD177 & sICAM-5 & \\
Fractalkine/CXCL-1 & Desmoglein-1 & Stratifin & \\
Granulins & Flt-3 ligand & & \\
IDS Kininogen, HMV & G-CFS-R & & \\
LAG-3 & IL-1Ra & & \\
Lamin-B1 & Leptin & \\
LRP1b & Lypd3 & \\
MATN2 & SH21A & \\
MMP-12 & SNP25 & \\
STAT1 TMR4 & TPBS2 & \\
\end{tabular}

*significantly increased also at ELISA** significantly increased at ELISA only in SSc with ILD versus $\mathrm{HC}$

The majority of proteins with higher levels in SSc with ILD compared to SSc with out ILD were involved in intracellular signaling and cell cycle (FCRL3, PDE11, Stratifin), along with higher MCP-3, a monocyte chemoattractant, and SICAM-5 ligand for the leukocyte adhesion protein LFA-1. Of note, we found that increased IL-22BP, antagonist of IL-22, and decreased BAFF levels characterized SSc with ILD.

Conclusion: Aptamer proteomic analysis allowed to define serum profiles differentiating SSc patients from healthy controls and SSc with ILD from SSc without ILD; the proteins identified are involved in SSc pathogenic pathways and after further investigation on larger cohorts they can be used as reliable biomarkers.

Characters from table content including title and footnotes: 631

Disclosure of Interests: None declared

DOI: 10.1136/annrheumdis-2021-eular.3099

\section{Imaging in axial spondyloarthritis - what is new?}

\section{OP0250 1 MRI VERTEBRAL CORNER INFLAMMATION AND FAT DEPOSITION ARE ASSOCIATED WITH WHOLE SPINE LOW DOSE CT DETECTED SYNDESMOPHYTES: A MULTILEVEL ANALYSIS}

R. Stal ${ }^{1}$, X. Baraliakos ${ }^{2}$, A. Sepriano ${ }^{1}$, F. A. Van Gaalen ${ }^{1}$, S. Ramiro ${ }^{1}$, R. Van den Berg', M. Reijnierse ${ }^{3}$, J. Braun ${ }^{2}$, R. B. M. Landewée, D. Van der Heijde ${ }^{1}$

${ }^{1}$ Leiden University Medical Center, Rheumatology, Leiden, Netherlands: ${ }^{2}$ Rheumazentrum Ruhrgebiet, Rheumatology, Herne, Germany; ${ }^{3}$ Leiden University Medical Center, Radiology, Leiden, Netherlands; ${ }^{4}$ Amsterdam University Medical Center, Rheumatology, Amsterdam, Netherlands

Background: A few studies have shown an association between vertebral corner inflammation (VCl) and vertebral corner fat deposition (VCFD) on MRI and syndesmophyte formation on cervical and lumbar conventional radiography.

Objectives: To investigate whether magnetic resonance imaging (MRI) patterns of $\mathrm{VCl}, \mathrm{VCFD}$ and a combination of both are associated with the development of new or grown syndesmophytes as detected by whole spine low dose computed tomography (IdCT), thereby studying these associations also in the thoracic spine.

Methods: Patients in the Sensitive Imaging in Ankylosing Spondylitis cohort underwent MRI at baseline, 1 year and 2 years, and IdCT at baseline and 2 years. MRI lesions were scored by 3 central readers, using the SPARCC method for $\mathrm{VCl}$ and the CanDen method for VCFD, and coded as absent or present per timepoint and per reader. MRI patterns over time (Table) were based on patterns studied by Machado et al. ${ }^{1}$ and deemed present if seen by $\geq 2$ out of 3 readers. The patterns reflect hypothetical associations between presence and absence of $\mathrm{VCl}$ and VCFD, independently and combined, on IdCT detected new or grown syndesmophytes. Individual reader change scores were used for IdCT images, scored by 2 central readers with the Computed Tomography Syndesmophyte Score. New (CTSS 0 to 1, 2 or 3) and grown (CTSS 1 to 2 or 3; 2 to 3 ) syndesmophytes were grouped together to represent bone formation. Corners not at risk 